\title{
CHAPTER 7 \\ Air Pollution, Oxidative Stress, and Public Health in the Anthropocene
}

\author{
Ulrich Pöschl
}

Summary Air pollution severely affects air quality, climate, and public health in the Anthropocene, which is the present era of globally pervasive anthropogenic influence on planet Earth. Thus, we need to understand how humanity can best deal with the sources and effects of air pollutants in relation to economic development, human welfare, and environmental preservation. Recent advances in scientific research provide deep insights into the underlying physical, chemical, and biological processes that link air pollution with health effects and reveal the relative importance of different pollutants and sources, including natural and anthropogenic contributions. This knowledge enables the development of efficient strategies and policies to mitigate and counteract the adverse effects of air pollution on the Earth system, climate, and human health ("planetary health"). Building on open access to scholarly publications and data, a global commons of scholarly knowledge in the sciences and humanities will help to augment, communicate, and utilize the scientific understanding. Moreover, public peer review, interactive discussion, and documentation of the scientific discourse on the internet can serve as examples and blueprints for rational and transparent approaches to resolving complex questions and issues ("epistemic web"). With regard to the development, societal communication, and political implementation of appropriate policies for air quality management, it seems worthwhile to emphasize that climate and health effects are two facets of global environmental change that can be and need to be handled together. The Anthropocene notion may help humanity to recognize both rationally and emotionally: We are shaping our planet and environment, so let us get it right.

U. Pöschl ( $\bowtie)$

Multiphase Chemistry Department, Max Planck Institute for Chemistry, Mainz, Germany

e-mail: u.poschl@mpic.de 


\section{Background}

Anthropogenic air pollution leads to a massive increase of atmospheric aerosol and oxidant concentrations on local, regional, and global scales. For example, the average mixing ratios of ozone in continental background air have increased by factors of $\sim 2-4$ from around $10-20 \mathrm{ppb}$ at the beginning of the nineteenth century to $30-40 \mathrm{ppb}$ in the twenty-first century, and the concentrations of fine particulate matter in polluted urban air are typically a factor of $\sim 10$ higher than in pristine air of remote continental and marine regions $\left(\sim 10-100 \mu \mathrm{g} \mathrm{m}^{-3} \mathrm{vs.} \sim 1-10 \mu \mathrm{g} \mathrm{m}^{-3}\right)$. The strong increase of these and other air pollutants is a characteristic feature of global environmental change in the Anthropocene, which is the present era of globally pervasive anthropogenic influence on planet Earth, including the atmosphere, biosphere, land, and oceans (Crutzen, 2002; Foley, Gronenborn, Andreae, et al., 2013; Pöschl \& Shiraiwa, 2015; Seinfeld \& Pandis, 2016; Waters et al., 2016 and references therein).

Figure 7.1a illustrates the cycling and effects of gas molecules and aerosol particles exchanged between the atmosphere and the Earth's surface, including the biosphere, hydrosphere, and pedosphere/lithosphere (Pöschl, 2005; Pöschl \& Shiraiwa, 2015). It involves primary emission from natural and anthropogenic sources as well as secondary formation via oxidation of precursors in the atmosphere. In the atmosphere, gases and aerosols undergo chemical and physical transformation ("aging"), which includes the interaction with solar radiation and atmospheric oxidants as well as cloud droplets and ice crystals (cloud processing). Besides mineral dust, sea spray, and combustion- and traffic-related particles, atmospheric aerosol also contains biological particles such as pollen, fungal spores, bacteria, and viruses, which are important for the functioning of ecosystems as well as the spread of animal, plant, and human diseases (Fröhlich-Nowoisky et al., 2016; Rodriguez-Caballero et al., 2018). The atmospheric cycling of gases, aerosols, clouds, and precipitation is essential for the evolution, current state, and future development of the atmosphere and climate as well as the biosphere and public health or "planetary health." Multiphase chemical reactions, transport, and transformations between gaseous, liquid, and solid matter are key to understanding the Earth system and climate as well as life and health on molecular and global levels, bridging a wide range of spatial and temporal scales from below nanometers to thousands of kilometers and from less than nanoseconds to years and millennia (Fig. 7.1b). From a chemical perspective, life and the metabolism of most living organisms can be regarded as multiphase processes involving gases such as oxygen and carbon dioxide; liquids such as water, blood, lymph, and plant sap; and solid or semisolid substances such as bone, tissue, skin, wood, and cellular membranes. On global scales, the biogeochemical cycling of chemical compounds and elements, which can be regarded as the metabolism of planet Earth, also involves chemical reactions, mass transport, and phase transitions within and across the atmosphere, biosphere, hydrosphere, and pedosphere/lithosphere (Pöschl \& Shiraiwa, 2015). 


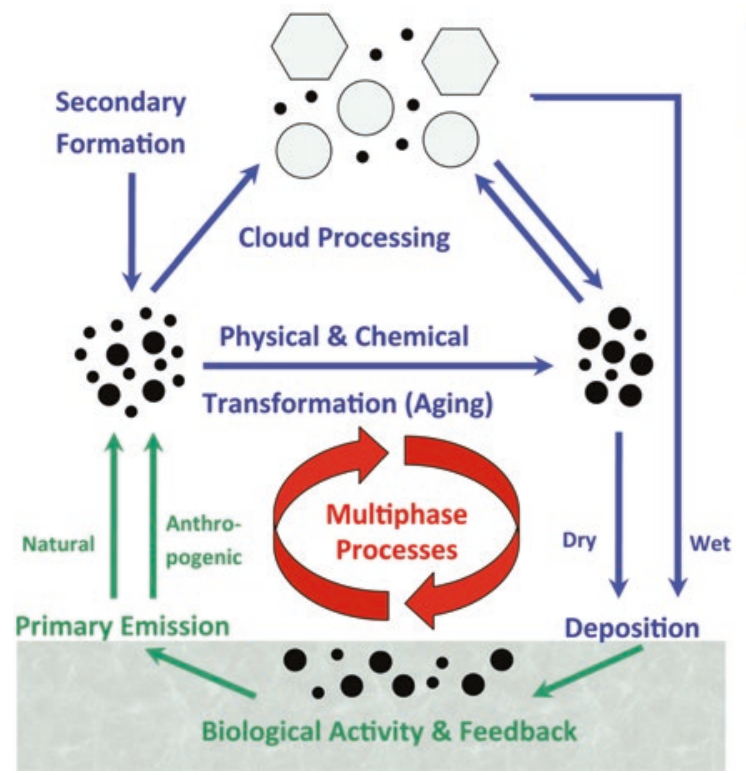

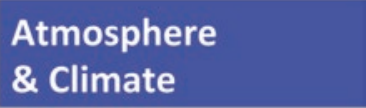

$>$ aerosols \& gases

$>$ clouds \& precipitation

radiation \& dynamics

Mechanistic understanding, quantitative prediction

\& human influence?

reproduction \& spread of organisms \& biomes

human, animal \& plant diseases

\section{Biosphere \&} Public Health

\section{Earth \& Climate}

\section{Life \& Health}

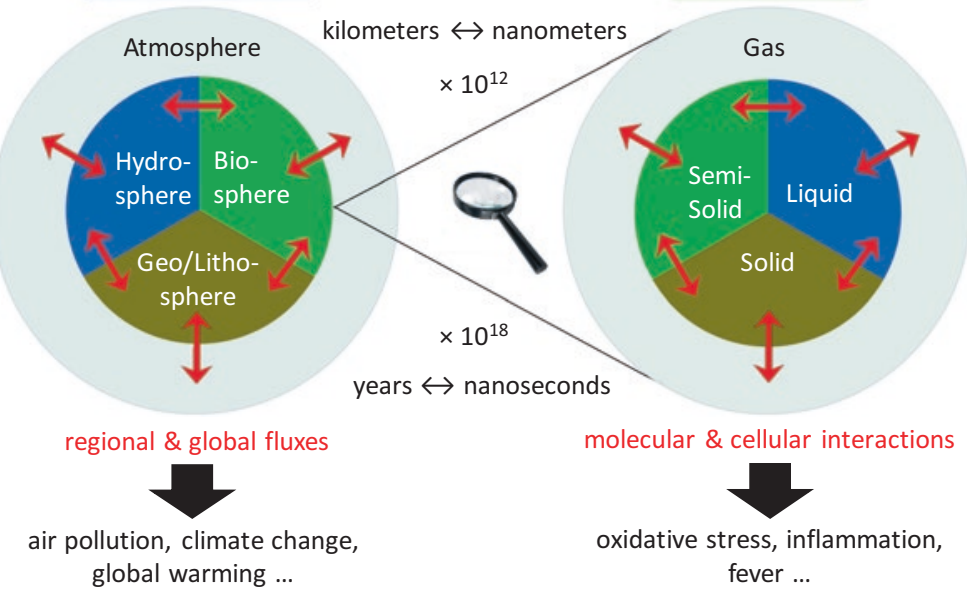

Fig. 7.1 (a) Atmospheric cycling of gases and particles, including natural constituents and anthropogenic air pollutants that undergo physical, chemical, and biological interactions. (b) Multiphase processes between gaseous, liquid, and solid substances influence the Earth system and climate as well as life and public health from molecular and cellular to regional and global scales (adapted from Pöschl \& Shiraiwa, 2015) 
Through biogeochemical and metabolic processes, air pollutants such as particulate matter, ozone, and nitrogen oxides can severely affect air quality, climate, and public health. They influence the regional and global distribution of solar radiation, energy, and water; and they enhance mortality, promote cardiovascular, respiratory and allergic diseases, and decrease agricultural crop yields (Pöschl \& Shiraiwa, 2015; Shiraiwa, Li, \& Tsimpidi, et al., 2017; West et al., 2016; and references therein). Globally, the annual number of premature deaths attributable to ambient air pollution are estimated to exceed 4 million per year, corresponding to over 100 million of disability-adjusted life-years (DALYs) lost every year (Cohen et al., 2017; Landrigan, Fuller, Acosta, et al., 2017; Lelieveld \& Pöschl, 2017; Lelieveld, Evans, Fnais, Giannadaki, \& Pozzer, 2015; Lelieveld, Haynes, \& Pozzer, 2018; Stanaway et al. 2018; and references therein). Recent studies suggest that the mortality rates attributable to air pollution are even higher (up to $\sim 9$ million per year; Burnett et al., 2018; Lelieveld et al., 2019). Thus, we need to understand how human activities can create a hazardous atmosphere affecting the health of people and planet Earth, and how humanity can best deal with the sources and effects of air pollution in relation to economic development, human welfare, and environmental preservation in the Anthropocene.

\section{Reactive Oxygen and Nitrogen Species}

Reactive oxygen and nitrogen species (ROS/RNS) are central to both atmospheric and physiological chemistry, and their coupling through human airways and epithelia is illustrated in Fig. 7.2a. These chemical species include highly reactive free radicals such as hydroxyl radicals $(\mathrm{OH})$ and nitrate radicals $\left(\mathrm{NO}_{3}\right)$ as well as more stable compounds such as hydrogen peroxide $\left(\mathrm{H}_{2} \mathrm{O}_{2}\right)$ and nitrous acid (HONO). They play a central role in the adverse health effects of air pollution and are produced in a wide range of atmospheric and physiological processes (Halliwell \& Gutteridge, 2015; Pöschl \& Shiraiwa, 2015; Shiraiwa, Li, Tsimpidi, et al., 2017; Shiraiwa, Ueda, Pozzer, et al., 2017; Sies et al., 2017; Su et al., 2011; Tong et al., 2017). In the atmosphere, ROS/RNS are generated via photochemical and multiphase reactions involving atmospheric oxidants, aerosols, and clouds. Ozone and related ROS/RNS are among the most noxious components of summer smog, and they are also involved in the secondary formation of air particulate matter by oxidation and condensation of gaseous precursors in the atmosphere (e.g., secondary organic aerosols and sulfate; Cheng et al., 2016; Hallquist et al., 2009). On the other hand, ROS/RNS are crucial for the oxidative self-cleaning of the atmosphere by increasing the water solubility of air pollutants and their removal by precipitation ("washout" or wet deposition). For example, hydroxyl radicals convert nitrogen dioxide into highly soluble nitric acid, which is efficiently absorbed by rain and snow. In fact, hydroxyl radicals are such strong oxidants that they react with and facilitate the removal of most air pollutants and are thus called the "detergent" of the atmosphere (Pöschl \& Shiraiwa, 2015; Seinfeld \& Pandis, 2016). 


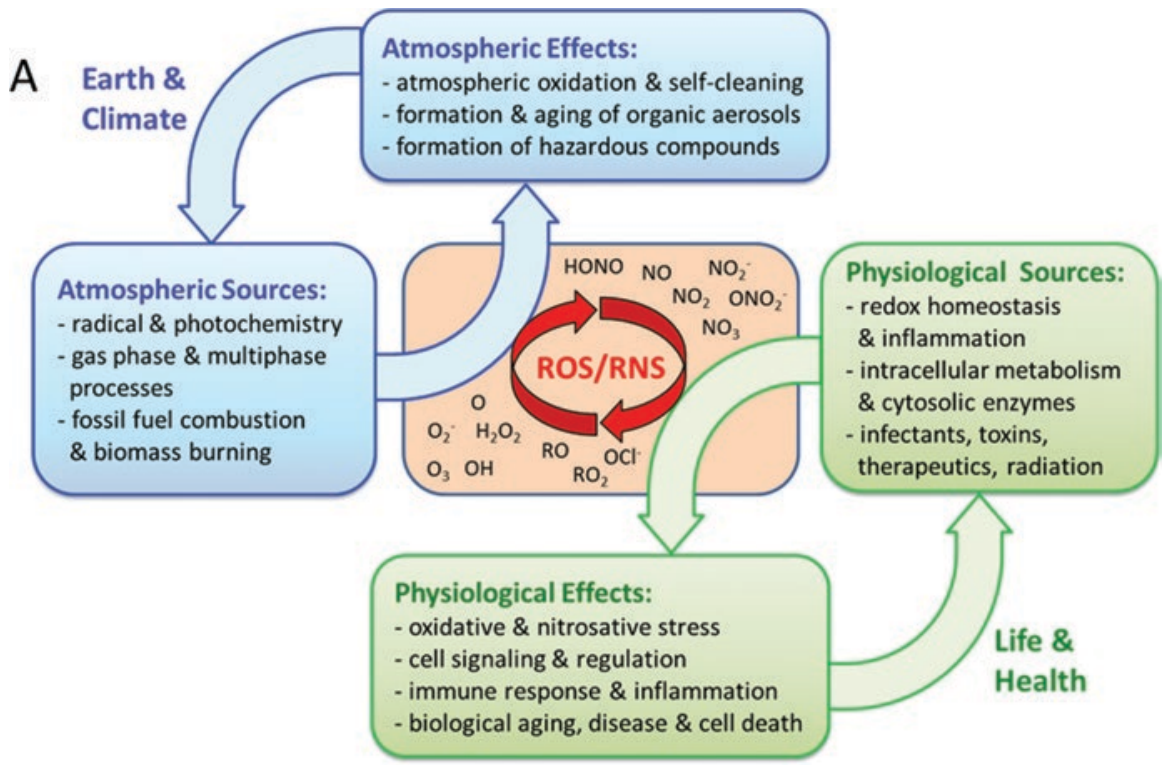

B

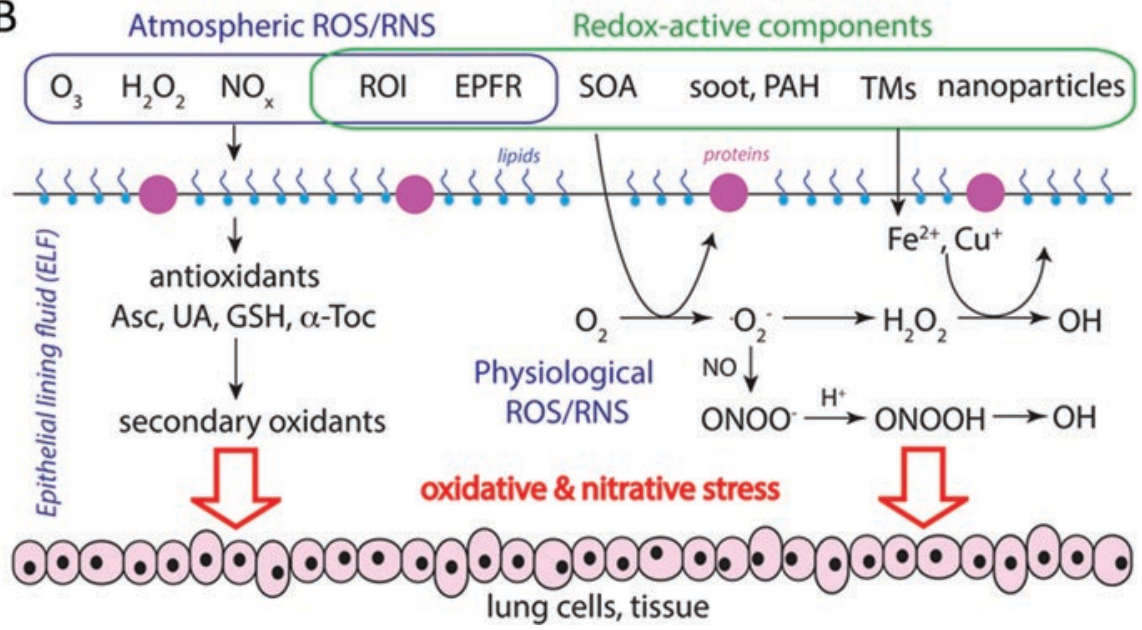

Fig. 7.2 (a) Sources, interactions, and effects of reactive oxygen and nitrogen species (ROS/RNS) at the interface of atmospheric and physiological chemistry with feedback loops involving the Earth system, climate, life, and health. (b) Interactions of atmospheric and physiological ROS/ RNS with antioxidants (ascorbate, uric acid, reduced glutathione, $\alpha$-tocopherol) in the epithelial lining fluid (ELF) of the human respiratory tract. Reactive pollutants such as ozone $\left(\mathrm{O}_{3}\right)$, hydrogen peroxide $\left(\mathrm{H}_{2} \mathrm{O}_{2}\right)$, nitrogen oxides $\left(\mathrm{NO}_{x}\right)$, reactive oxygen intermediates (ROI), environmentally persistent free radicals (EPFR), secondary organic aerosol (SOA), soot, quinones, and transition metals can induce ROS/RNS formation in vivo, leading to oxidative stress and biological aging (Pöschl \& Shiraiwa, 2015; Reinmuth-Selzle et al., 2017) 
Physiological sources of ROS/RNS include metabolic, signaling, and inflammatory processes. In the human immune system, ROS/RNS are used in defense against pathogens by oxidizing relevant biomolecules (DNA, proteins, lipids) and rendering the pathogens biologically less active or inactive. For example, $\mathrm{H}_{2} \mathrm{O}_{2}, \mathrm{OH}$ radicals and related ROS are involved in the elimination of pathogenic microbes (Halliwell \& Gutteridge, 2015). Under homeostatic conditions, the production of ROS/RNS is balanced by antioxidants. Air pollution, however, can cause excessive production or uptake of ROS/RNS and an imbalance between oxidants and antioxidants (oxidative stress), leading to cell death, biological aging, inflammation, and various diseases (Pöschl \& Shiraiwa, 2015; Reinmuth-Selzle et al., 2017; Sies et al., 2017; West et al., 2016). In other words, adequate levels of ROS/RNS are essential for the functioning and self-cleaning of both the atmosphere and the human organism, but excess concentrations of ROS/RNS are detrimental to human health.

Fine particulate matter suspended in the air contains reactive components such as transition metals (TM), polycyclic aromatic hydrocarbons (PAH), semiquinones, nanoparticles, and related substances. In the atmosphere, aerosols undergo transport and transformation, which may lead to a change in their chemical composition and toxicity as well as their optical properties and climate effects depending on temperature, humidity, and particle phase state (Ditas et al., 2018; Mu et al., 2018; Shiraiwa, Ammann, Koop, \& Pöschl, 2011; Shiraiwa, Li, Tsimpidi, et al., 2017; Shiraiwa, Ueda, Pozzer, et al., 2017; Socorro et al., 2017; Tong et al., 2017). Upon inhalation and deposition in the human respiratory tract, air pollutants can induce and sustain chemical reactions that produce ROS in the epithelial lining fluid (ELF) covering the airways. As illustrated in Fig. 7.2b, the reactive pollutants and ROS undergo a multitude of chemical reactions in the ELF. A quantitative analysis and assessment of these processes was recently achieved in investigations using a kinetic multilayer model of surface and bulk chemistry in the ELF (KM-SUB-ELF) to obtain chemical exposure-response relations between ambient concentrations of air pollutants and the production rates and concentrations of ROS in the ELF of the human respiratory tract (Lakey et al., 2016).

As illustrated in Fig. 7.3, the total concentration of ROS generated by redoxactive substances contained in fine particulate matter (PM2.5) deposited in the ELF can increase by more than a factor of 20 from $\sim 10 \mathrm{nmol} \mathrm{L}{ }^{-1}$ under clean conditions up to almost $\sim 250 \mathrm{nmol} \mathrm{L}{ }^{-1}$ under highly polluted conditions. The green-striped horizontal bar indicates ROS concentration levels characteristic of the ELF or bronchoalveolar lavage of healthy humans, respectively, which are around $\sim 100 \mathrm{nmol} \mathrm{L}^{-1}$. Compared to this reference level, the ROS concentrations generated by redox-active particulate matter inhaled from pristine marine or rainforest air $\left(\mathrm{PM} 2.5<10 \mu \mathrm{g} \mathrm{m}^{-3}\right)$ are much lower and appear negligible with regard to airway oxidative stress. In moderately polluted air (PM2.5 $\approx 10-50 \mu \mathrm{g} \mathrm{m}^{-3}$ ), the particle-generated ROS concentrations can be of similar magnitude or higher than the physiological background level and may thus significantly contribute to oxidative stress depending on aerosol 


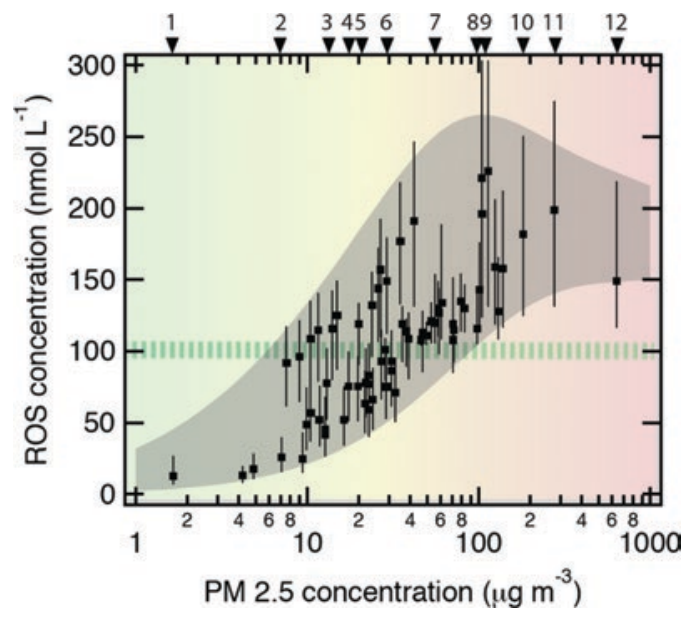

Fig. 7.3 Chemical exposure-response relationships between ambient concentrations of fine particulate matter (PM2.5) and the concentration of reactive oxygen species (ROS) in the epithelial lining fluid (ELF) of the human respiratory tract. The green-striped horizontal bar indicates the ROS level characteristic for healthy humans $\left(\sim 100 \mathrm{nmol} \mathrm{L}^{-1}\right)$. The gray envelope represents the range of aerosol-induced ROS concentrations obtained with approximate upper and lower limit mass fractions of redox-active components observed in ambient PM2.5. The data points represent various geographic locations for which measured or estimated mass fractions are available, including (1) Amazon, Brazil (pristine rainforest air); (2) Edinburgh, UK; (3) Toronto, Canada; (4) Tokyo, Japan; (5) Budapest, Hungary; (6) Hong Kong, China; (7) Milan, Italy; (8) Guangzhou, China; (9) Pune, India; (10) Beijing, China; (11) New Delhi, India; (12) Sumatra, Indonesia (biomass burning/peat fire smoke) (Lakey et al., 2016)

concentration and chemical composition (see error bars and grey-shaded area). In heavily polluted air (PM2.5 $>50 \mu \mathrm{g} \mathrm{m}^{-3}$ ), the particle-generated ROS concentrations are as high as the ROS concentrations observed in the bronchoalveolar lavage of patients with acute inflammatory diseases in respiratory tract $\left(100-250 \mathrm{nmol} \mathrm{L}^{-1}\right)$. The pathologically high ROS levels calculated for ELF in airways exposed to high ambient aerosol concentrations are consistent with epidemiology-based air quality standards and regulations of the World Health Organization (WHO), aiming at PM2.5 concentrations less than $10 \mu \mathrm{g} \mathrm{m}^{-3}$ averaged over a year (Lakey et al., 2016; WHO, 2013; 2017). Further investigations building on the scientific approach and exposure-response relations outlined above will help to identify key species and processes to be targeted in efficient strategies and policies for air quality control and improvement. For example, they may help to resolve the relative importance and nonlinear interactions of different types and sources of air pollutants such as combustion engine exhaust, brake-wear, and dust emitted or suspended by road or railway traffic. 


\section{Allergic Diseases}

Allergies constitute a major health issue in most modern societies, and related diseases such as allergic rhinitis and atopic asthma have strongly increased during the past decades. Among the environmental risk factors for allergic diseases are reduced childhood exposure to pathogens and parasites (hygiene hypothesis), nutritional factors, psychological or social stress, and environmental pollutants (diesel exhaust particles, ozone, nitrogen oxides, etc.), which can effectively lead to an over- or under-stimulation of the immune system (Reinmuth-Selzle et al., 2017). As outlined in Fig. 7.4, air pollution and climate change can influence the bioavailability and potency of allergens and adjuvants in multiple ways, including changes in vegetation cover, pollination and sporulation periods, and chemical modification or aggregation. Moreover, air pollutants can act as adjuvants and skew physiological

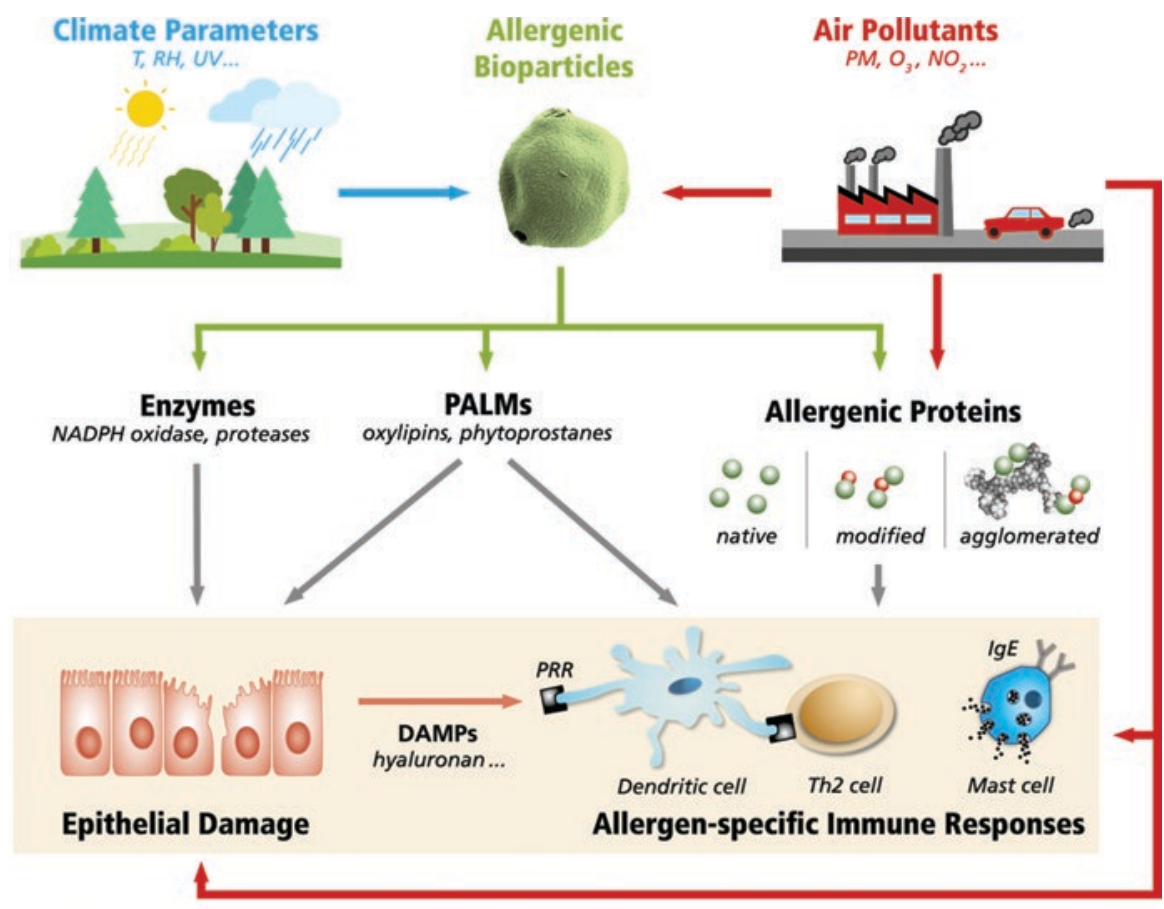

\section{Proinflammatory \& Immunomodulatory Effects}

Fig. 7.4 Pathways through which climate parameters and air pollutants can influence the release, potency, and effects of allergens and adjuvants: temperature $(\mathrm{T})$, relative humidity $(\mathrm{RH})$, ultraviolet (UV) radiation, particulate matter (PM), ozone and nitrogen oxides $\left(\mathrm{O}_{3}, \mathrm{NO} x\right)$, reduced nicotinamide adenine dinucleotide phosphate (NADPH) oxidase, pollen-associated lipid mediators (PALMs), damage-associated molecular patterns (DAMPs), pattern recognition receptors (PRR), type $2 \mathrm{~T}$ helper (Th2) cells, immunoglobulin E (IgE), allergenic proteins (green dots), and chemical modifications (red dots) (Reinmuth-Selzle et al., 2017) 
processes and the immune system towards the development of allergies, for example, by oxidative stress, inflammation, and disruption of protective epithelial barriers. Environmental allergens are mostly proteins derived from plants, animals, and fungi that can trigger chemical and biological reaction cascades in the immune system leading to allergic sensitization and formation of $\operatorname{IgE}$ antibodies. Prominent examples are major allergens of birch pollen (Bet v 1), timothy grass pollen (Phl $\mathrm{p}$ 1), ragweed (Ambrosia, Amb a 1), molds (Alternaria alternata, Alt a 1; Cladosporium herbarum, Cla h 1; Aspergillus fumigatus, Asp f 1), and dust mites (Der p 1).

Figure 7.5 provides a simplified overview of cellular and molecular interactions that are central to the processes of sensitization and response in IgE-mediated allergies (type I hypersensitivities). Normally, IgE antibodies and related immune reactions are involved in the defense against parasitic infections, and allergic reactions can thus be regarded as a "false alarm" of the immune system. Interactions between protein macromolecules acting as allergens, antibodies, cytokines, or receptors play a key role in the innate and adaptive immune responses involved in the development of allergies. Chemical modification by air pollutants can lead to changes in the molecular structure and interactions of protein macromolecules that trigger such false alarms (Reinmuth-Selzle et al., 2017 and references therein).

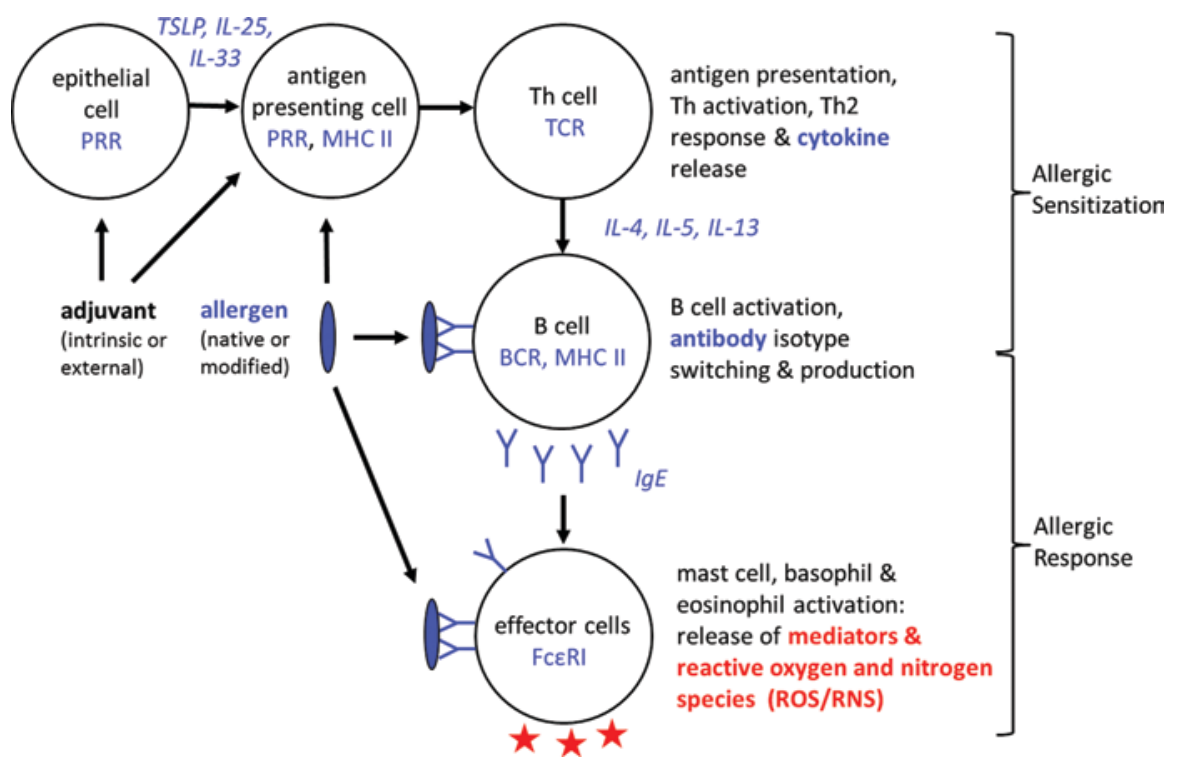

Fig. 7.5 Cellular and molecular interactions involved in allergic sensitization and response of IgEmediated allergies (type I hypersensitivities): blue color indicates protein macromolecules acting as allergens, antibodies, cytokines, or receptors; red color indicates pro-inflammatory mediators and reactive oxygen or nitrogen species (ROS/RNS) (Reinmuth-Selzle et al., 2017) 
Rising concentrations of atmospheric aerosols and oxidants are likely to promote the chemical modification of proteins in the atmosphere as well as in the human body due to elevated ROS/RNS levels and oxidative stress, especially in the airways (ELF) as outlined above. For example, elevated $\mathrm{O}_{3}$ and $\mathrm{NO}_{2}$ concentrations can enhance the allergenic potential of proteins through nitration and cross-linking of allergenic proteins through the aromatic amino acid tyrosine as illustrated in Fig. 7.6 (Franze, Weller, Niessner, \& Pöschl, 2005; Liu et al., 2017; Reinmuth-Selzle, Ackaert, \& Kampf, 2014; Reinmuth-Selzle et al., 2017). Ongoing experimental and theoretical studies provide new insights into the mechanism of these and related processes, which will help to elucidate and counteract the influence of air pollutants on the development and aggravation of allergic diseases.

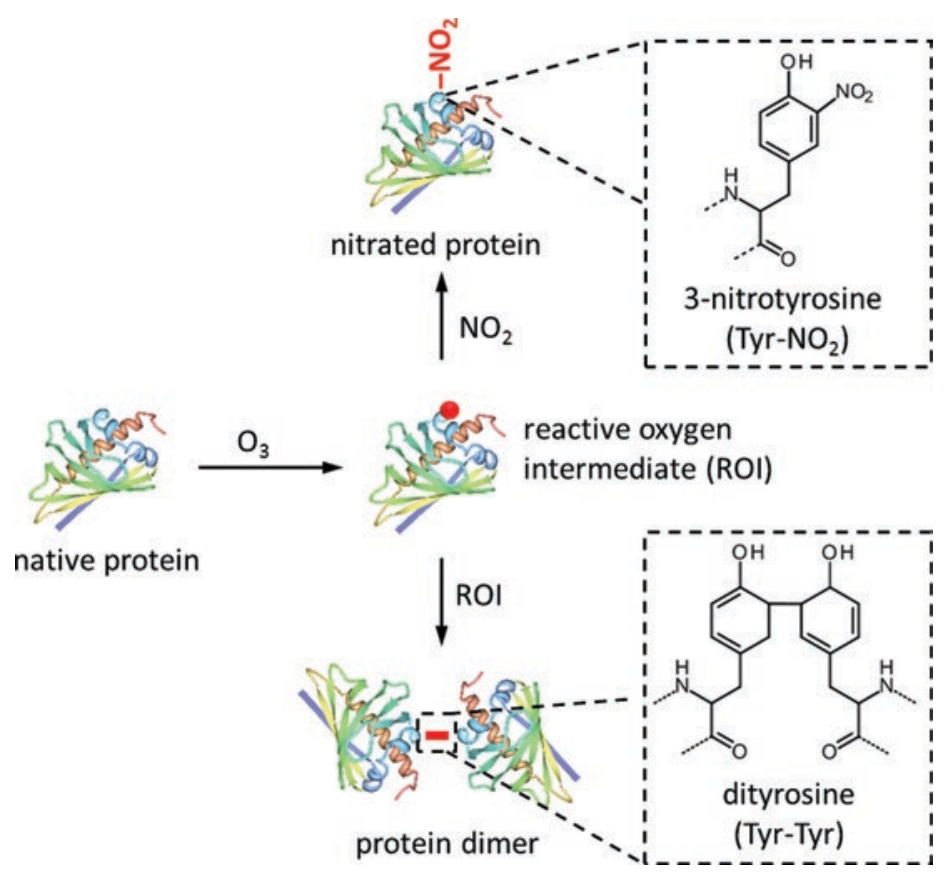

Fig. 7.6 Posttranslational modification of proteins exposed to ozone $\left(\mathrm{O}_{3}\right)$ and nitrogen dioxide $\left(\mathrm{NO}_{2}\right)$. The initial reaction with $\mathrm{O}_{3}$ leads to the formation of reactive oxygen intermediates (ROI, tyrosyl radicals), which can further react with each other to form cross-linked proteins (dityrosine) or with $\mathrm{NO}_{2}$ to form nitrated proteins (nitrotyrosine). The shown protein is Bet $\mathrm{v} 1.0101$, for which nitration and cross-linking were found to influence the immunogenicity and allergenic potential. Red dot indicates a tyrosyl radical; red bar indicates dityrosine cross-link (Reinmuth-Selzle et al., 2017) 


\section{Conclusions}

In air quality, climate, and health studies, it is often challenging to separate natural and anthropogenic effects and variations. Unperturbed natural conditions are difficult to find or reconstruct from current and recent observations of the environment, which has already undergone massive anthropogenic change on global scales. All the more, it is important to fully unravel and quantify the processes and interactions influencing the current state as well as the history and future development of the Earth system, climate, air quality, and public health. This requires interdisciplinary exchange and collaboration across the Earth, environmental, and life sciences. Recent advances in field observations, laboratory experiments, and mathematical model simulations provide deep insights into the underlying physical, chemical, and biological processes. They enable the development and refinement of target-oriented ways and efficient approaches of effectively mitigating and counteracting the adverse effects of air pollutants. Building on open access to scholarly publications and data, a global commons of scholarly knowledge in the sciences and humanities will help to augment, communicate, and utilize the scientific understanding (Berlin Declaration, 2003; oa2020.org). Moreover, public peer review, interactive discussion, and documentation of the scientific discourse on the internet can serve as examples and blueprints for rational and transparent approaches to resolving complex questions and issues (Pöschl, 2012). Combining the internet with open science will ultimately reflect both what we know and how we know it ("epistemic web"; Hyman \& Renn, 2012). In any case, scholars and practitioners in the natural, social, and medical sciences as well as humanities and politics should closely collaborate to transfer the scientific knowledge of air pollutant sources and effects into effective strategies and policies of air quality management and control. This should be pursued in analogy to the successful example of protecting the ozone layer from destruction by chlorofluorocarbons in the late twentieth century rather than the gridlocked struggle for climate protection in the early twenty-first century. In this context, it may be worthwhile to emphasize not only the need to mitigate negative side effects of human activities but also the opportunities for actively using scientific knowledge and technology to protect planet Earth for a sustainable development and healthy future of humanity and its planetary home ("planetary health"). Thus, the Anthropocene notion may help humanity to recognize both rationally and emotionally: We are shaping our planet and environment, so let us get it right.

Acknowledgements This chapter provides an overview and synthesis of recent scientific exchange, studies, and publications of the author with numerous colleagues who are gratefully acknowledged-in particular, P. J. Crutzen, Y. Cheng, H. Su, M. Shiraiwa, P. Lakey, K. ReinmuthSelzle, C. Kampf, K. Lucas, J. Fröhlich, T. Berkemeier, H. Tong, C. Pöhlker, M. Pöhlker, M. Weller, A. Duschl, I. Bellinghausen, J. Saloga, D. Schuppan, M. O. Andreae, and J. Lelieveld. The chapter is dedicated to Paul J. Crutzen, whose curiosity, ingenuity, and wisdom have helped to prevent ozone layer destruction and nuclear winter, and will help to avoid the perils and grasp the opportunities of the Anthropocene. 


\section{References}

Berlin Declaration on Open Access to Knowledge in the Sciences and Humanities. (2003). Retrieved on February 16, 2020 from https://openaccess.mpg.de/Berlin-Declaration

Burnett, R., Chena, H., Szyszkowicz, M., Fann, N., Hubbell, B., Pope, I. I. I. C. A., et al. (2018). Global estimates of mortality associated with long-term exposure to outdoor fine particulate matter. Proceedings of the National Academy of Sciences of the United States of America, 115, 9592-9597.

Cheng, Y., Zheng, G., Wei, C., Mu, Q., Zheng, B., Wang, Z., et al. (2016). Reactive nitrogen chemistry in aerosol water as a source of sulfate during haze events in China. Science Advances, 2. https://doi.org/10.1126/sciadv.1601530

Cohen, A. J., Brauer, M., Burnett, R., Anderson, H. R., Frostad, J., Estep, K., et al. (2017). Estimates and 25-year trends of the global burden of disease attributable to ambient air pollution: An analysis of data from the Global Burden of Diseases Study 2015. Lancet, 389, 1907-1918. https://doi.org/10.1016/S0140-6736(17)30505-6

Crutzen, P. J. (2002). Geology of mankind. Nature, 415, 23-23.

Ditas, J., Ma, N., Zhang, Y., Assmann, D., Neumeier, M., Riede, H., et al. (2018). Strong impact of wildfires on the abundance and aging of black carbon in the lowermost stratosphere. Proceedings of the National Academy of Sciences of the United States of America, 115, E11595-E11603. https://doi.org/10.1073/pnas.1806868115

Foley, S. F., Gronenborn, D., Andreae, M. O., et al. (2013). The Palaeoanthropocene-The beginnings of anthropogenic environmental change. Anthropocene, 3, 83-88.

Franze, T., Weller, M. G., Niessner, R., \& Pöschl, U. (2005). Protein nitration by polluted air. Environmental Science and Technology, 39, 1673-1678. https://doi.org/10.1021/es0488737

Fröhlich-Nowoisky, J., Kampf, C. J., Weber, B., Huffman, J. A., Pöhlker, C., Andreae, M. O., et al. (2016). Bioaerosols in the earth system: Climate, health, and ecosystem interactions. Atmospheric Research, 182, 346-376.

Halliwell, B., \& Gutteridge, J. M. C. (2015). Free radicals in biology and medicine. Oxford: Oxford University Press.

Hallquist, M., Wenger, J. C., Baltensperger, U., Rudich, Y., Simpson, D., Claeys, M., et al. (2009). The formation, properties and impact of secondary organic aerosol: Current and emerging issues. Atmospheric Chemistry and Physics, 9, 5155-5236. https://doi.org/10.5194/ acp-9-5155-2009

Hyman, M. D., \& Renn, J. (2012). Toward an epistemic web. In J. Renn (Ed.), The globalization of knowledge in history. Edition Open Access, ISBN: 978-3-945561-23-2.

Lakey, P. S. J., Berkemeier, T., Tong, H., Arangio, A. M., Lucas, K., Pöschl, U., et al. (2016). Chemical exposure-response relationship between air pollutants and reactive oxygen species in the human respiratory tract. Scientific Reports, 6, 32916. https://doi.org/10.1038/srep32916.309

Landrigan, P. J., Fuller, R., Acosta, N. J. R., Adeyi, O., Arnold, R., Basu, N., et al. (2017). The Lancet Commission on pollution and health. Lancet, 391, 462-512. https://doi.org/10.1016/ S0140-6736(17)32345-0

Lelieveld, J., Evans, J. S., Fnais, M., Giannadaki, D., \& Pozzer, A. (2015). The contribution of outdoor air pollution sources to premature mortality on a global scale. Nature, 525, 367-371. https://doi.org/10.1038/nature15371

Lelieveld, J., Haynes, A., \& Pozzer, A. (2018). Age-dependent health risk from ambient air pollution: A modelling and data analysis of childhood mortality in middle-income and low-income countries. Lancet Planet Health, 2, E292-E300. https://doi.org/10.1016/S2542-5196(18)30147-5

Lelieveld, J., Klingmüller, K., Pozzer, A., Pöschl, U., Fnais, M., Daiber, A., et al. (2019). Cardiovascular disease burden from ambient air pollution in Europe reassessed using novel hazard ratio functions. European Heart Journal, 40, 1590-1596. https://doi.org/10.1093/ eurheartj/ehz135

Lelieveld, J., \& Pöschl, U. (2017). Chemists can help to solve the air-pollution health crisis. Nature, 551, 291-293. 
Liu, F., Lakey, P. S. J., Berkemeier, T., Tong, H. J., Kunert, A. T., Meusel, H., et al. (2017). Atmospheric protein chemistry influenced by anthropogenic air pollutants: Nitration and oligomerization upon exposure to ozone and nitrogen dioxide. Faraday Discussions, 200, 413-427. https://doi.org/10.1039/c7fd00005g

Mu, Q., Shiraiwa, M., Octaviani, M., Ma, N., Ding, A. J., Su, H., et al. (2018). Temperature effect on phase state and reactivity controls atmospheric multiphase chemistry and transport of PAHs. Sciences Advances, 4, eaap7314. https://doi.org/10.1126/sciadv.aap7314

Pöschl, U. (2005). Atmospheric aerosols: Composition, transformation, climate and health effects. Angewandte Chemie International Edition, 44, 7520-7540.

Pöschl, U. (2012). Multi-stage open peer review: Scientific evaluation integrating the strengths of traditional peer review with the virtues of transparency and self-regulation. Frontiers in Computational Neuroscience. https://doi.org/10.3389/fncom.2012.00033

Pöschl, U., \& Shiraiwa, M. (2015). Multiphase chemistry at the atmosphere-biosphere interface influencing climate and public health in the Anthropocene. Chemical Reviews, 115, 44404475. https://doi.org/10.1021/cr500487s

Reinmuth-Selzle, K., Ackaert, C., Kampf, C. J., Lakey, P. S. J., Lai, S., Liu, F., et al. (2014). Nitration of the birch pollen allergen Bet v 1.0101: Efficiency and site-selectivity of liquid and gaseous nitrating agents. Journal of Proteome Research, 13, 1570-1577. https://doi. org/10.1021/pr401078h

Reinmuth-Selzle, K., Kampf, C. J., Lucas, K., Lang-Yona, N., Fröhlich-Nowoisky, J., Shiraiwa, M., et al. (2017). Air pollution and climate change effects on allergies in the anthropocene: Abundance, interaction, and modification of allergens and adjuvants. Environmental Science and Technology, 51, 4119-4141. https://doi.org/10.1021/acs.est.6b04908

Rodriguez-Caballero, E., Belnap, J., Budel, B., Crutzen, P. J., Andreae, M. O., Pöschl, U., et al. (2018). Dryland photoautotrophic soil surface communities endangered by global change. Nature Geoscience, 11, 185+. https://doi.org/10.1038/s41561-018-0072-1

Seinfeld, J. N., \& Pandis, S. N. (2016). Atmospheric chemistry and physics: From air pollution to climate change. New York: Wiley.

Shiraiwa, M., Ammann, M., Koop, T., \& Pöschl, U. (2011). Gas uptake and chemical aging of semi-solid organic aerosol particles. Proceedings of the National Academy of Sciences of the United States of America, 108, 11003-11008.

Shiraiwa, M., Li, Y., Tsimpidi, A. P., Berkemeier, T., Pandis, S. N., Lelieveld, J., et al. (2017). Global distribution of particle phase state in atmospheric secondary organic aerosols. Nature Communication, 8, 15002. https://doi.org/10.1038/ncomms15002

Shiraiwa, M., Ueda, K., Pozzer, A., Lammel, G., Kampf, C. J., Fushimi, A., et al. (2017). Aerosol health effects from molecular to global scales. Environmental Science \& Technology, 51, 13545-13567. https://doi.org/10.1021/acs.est.7b04417

Sies, H., et al. (2017). Oxidative stress. Annual Review of Biochemistry, 86, 715-748.

Socorro, J., Lakey, P. S. J., Han, L., Berkemeier, T., Lammel, G., Zetzsch, C., et al. (2017). Heterogeneous $\mathrm{OH}$ oxidation, shielding effects and implications for the atmospheric fate of terbuthylazine and other pesticides. Environmental Science \& Technology, 51, 13749-13754. https://doi.org/10.1021/acs.est.7b04307

Stanaway, J. D., et al. (2018). Global, regional, and national comparative risk assessment of 84 behavioural, environmental and occupational, and metabolic risks or clusters of risks for 195 countries and territories, 1990-2017: A systematic analysis for the Global Burden of Disease Study 2017. Lancet, 392, 1923-1994. https://doi.org/10.1016/S0140-6736(18)32225-6

Su, H., Cheng, Y., Oswald, R., Behrendt, T., Trebs, I., Meixner, F. X., et al. (2011). Soil nitrite as a source of atmospheric HONO and OH radicals. Science, 333, 1616-1618.

Tong, H. J., Lakey, P. S. J., Arangio, A. M., Socorro, J., Kampf, C. J., Berkemeier, T., et al. (2017). Reactive oxygen species formed in aqueous mixtures of secondary organic aerosols and mineral dust influencing cloud chemistry and public health in the Anthropocene. Faraday Discussions, 200, 251-270. https://doi.org/10.1039/c7fd00023e 
Waters, C. N., Zalasiewicz, J., Summerhayes, C., Barnosky, A. D., Poirier, C., Galuszka, A., et al. (2016). The Anthropocene is functionally and stratigraphically distinct from the Holocene. Science, 351, 6269. https://doi.org/10.1126/science.aad2622

West, J. J., Cohen, A., Dentener, F., Brunekreef, B., Zhu, T., Armstrong, B., et al. (2016). What we breathe impacts our health: Improving understanding of the link between air pollution and health. Environmental Science and Technology, 50, 4895-4904.

World Health Organization. (2013). Review of evidence on health aspects of air pollution-REVIHAAP project. Copenhagen, Denmark: WHO Regional Office for Europe.

World Health Organization. (2017). Evolution of WHO air quality guidelines: Past, present and future. Copenhagen, Denmark: WHO Regional Office for Europe.

Open Access This chapter is licensed under the terms of the Creative Commons Attribution 4.0 International License (http://creativecommons.org/licenses/by/4.0/), which permits use, sharing, adaptation, distribution and reproduction in any medium or format, as long as you give appropriate credit to the original author(s) and the source, provide a link to the Creative Commons license and indicate if changes were made.

The images or other third party material in this chapter are included in the chapter's Creative Commons license, unless indicated otherwise in a credit line to the material. If material is not included in the chapter's Creative Commons license and your intended use is not permitted by statutory regulation or exceeds the permitted use, you will need to obtain permission directly from the copyright holder.

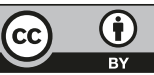

